\title{
Fetal anaemia due to pyruvate kinase deficiency
}

Florinda Gilsanz, Manuel A Vega, Elvira Gomez-Castillo, Jose A Ruiz-Balda, Felix Omeñaca

\begin{abstract}
Pyruvate kinase deficiency was diagnosed in an infant by umbilical vessel sampling at 30 weeks' gestation. Although three previous hydropic siblings had been stillborn or died in the neonatal period, this infant survived with transfusion dependent haemolytic anaemia. Prompt fetal diagnosis of pyruvate kinase deficiency is feasible and allows better management of hydrops fetalis due to this disorder. (Arch Dis Child 1993; 69: 523-524)
\end{abstract}

Anaemia requiring exchange transfusion is not unusual in newborns with pyruvate kinase deficiency; severe pyruvate kinase deficiency can cause hydrops fetalis and early neonatal death. ${ }^{1}$

Ultrasonography has made umbilical cord blood available for the prenatal diagnosis of inherited haematological disorders and is currently being used to monitor haemoglobin in rhesus isoimmunised fetuses. Although red cell enzyme tests require only small quantities of blood these are hardly ever performed even in anaemic, non-immune, hydrops fetalis. We report the diagnosis of severe fetal anaemia due to pyruvate kinase deficiency in blood obtained by umbilical vessel sampling at 30 weeks' gestation, on the fourth pregnancy of a couple whose three previous children had died of hydrops fetalis of unknown aetiology.

\section{Case report}

The mother had been referred to our hospital because three previous pregnancies had resulted in stillbirth or early neonatal death due to nonimmune anaemic hydrops fetalis of unknown aetiology. Her first child, a boy born at 32 weeks' gestation, was hydropic. His haemoglobin concentration was $92 \mathrm{~g} / \mathrm{l}$, blood group A $\mathrm{Rh}$ positive; direct Coombs test was positive due to anti-A. Two exchange transfusions were performed but the patient died due to intracranial haemorrhage 10 days later. Her second child, a stillborn girl was delivered at term. Postmortem examination showed marked extramedullary haematopoiesis (liver, spleen, and pericardium) suggestive of chronic fetal hypoxia. The third child, a boy, was born at 37 weeks' gestation. At birth haemoglobin was 69 $\mathrm{g} / \mathrm{l}$ and a great number of erythroblasts were seen on the peripheral blood smear; his blood group was $0 \mathrm{Rh}$ positive and direct Coombs test was negative. Exchange transfusions were performed, but the patient died due to heart failure.

The mother and father were first cousins and came from the centre of Spain. Both parents had normal haemoglobin concentra- tions, red cell indexes, and reticulocytes and no further studies were done to rule out other causes of hereditary haemolytic anaemia. Cytogenetic analysis showed normal karyotype. Congenital infection due to syphilis, Toxoplasma gondii, cytomegalovirus, or hepatitis B virus was ruled out.

On ultrasonography at 30 weeks' gestation the fetus showed no signs of hydrops but an increased heart rate was noticed by cardiotocography; this, added to the history of previous fetal losses, led to the performance of umbilical blood sampling. Fetal blood drawn from the umbilical vessels under ultrasound control had a haemoglobin concentration of 64 $\mathrm{g} / \mathrm{l}$, mean corpuscular volume $117 \mathrm{fl}, 95 \%$ reticulocytes, and $0.92 \times 10^{9} / 1$ erythroblasts. A blood smear showed macrocytosis with echinocytes and acanthocytes. The blood group was $\mathrm{A} R \mathrm{Rh}$ positive and the direct Coombs test negative. Haemoglobin electrophoresis showed only $\mathrm{HbF}$. A specific pyruvate kinase assay found no measurable enzymatic activity. ${ }^{2}$ Glucose-6-phosphate dehydrogenase activity was $26.55 \mathrm{IU} / \mathrm{g}$ haemoglobin (normal range $8 \cdot 35 \pm 1 \cdot 60$ ).

Within the next 24 hours a girl was delivered by caesarean section. Her birth weight was $1500 \mathrm{~g}$ and paleness, jaundice, oedema, and hepatomegaly were observed. Exchange transfusion was carried out in the immediate postnatal period. On a pretransfusion blood sample pyruvate kinase activity was $<1 \mathrm{IU} / \mathrm{g}$ haemoglobin (table). She had hyaline membrane disease and was treated with two doses of surfactant and mechanical ventilation.

At 6 months of age the patient has a severe transfusion dependent haemolytic anaemia but when she grows older, and perhaps with the help of splenectomy, she may be able to maintain a low but stable haemoglobin concentration.

The parents had no anaemia or reticulocytosis and had normal red cell morphology; pyruvate kinase activity was $50 \%$ of normal in each parent with normal kinetics and thermal stability.

\section{Discussion}

Pyruvate kinase deficiency is inherited as an autosomal recessive disorder and is found all over the world. Diagnosis of pyruvate kinase is based on the demonstration of reduced activity or qualitative anomalies of the specific red cell enzyme. Most pyruvate kinase deficient patients have less than $25 \%$ of the normal red enzyme activity, although there is poor correlation between pyruvate kinase activity and clinical severity. ${ }^{1}$ 
Haematological values and pyruvate kinase activity in the propositus and her parents

\begin{tabular}{lccc}
\hline Subject & $\begin{array}{l}\text { Haemoglobin } \\
(\mathrm{g} /)\end{array}$ & $\begin{array}{l}\text { Reticulocytes } \\
\left(10^{9} \Omega\right)\end{array}$ & $\begin{array}{c}\text { Pyruvate } \\
\text { kinase }^{\star}\end{array}$ \\
\hline Proband & & & \\
30 Weeks (fetal) & 64 & 1539 & $<1$ \\
$\quad$ At birth & 72 & 2000 & $<1$ \\
Father & 165 & 73 & $7 \cdot 8$ \\
Mother & 131 & 121 & $8 \cdot 3$ \\
\hline
\end{tabular}

* Measured as $\mu \mathrm{mol}$ of substrate converted/hour/g haemoglobin. Normal newborn pyruvate kinase values in our laboratory bin. Normal newborm

The patient's parents are asymptomatic heterozygous carriers of pyruvate kinase deficiency and although it is unusual, the clinica data point towards pyruvate kinase deficiency as the cause of death of the three siblings with anaemic hydrops fetalis.

Prenatal studies performed on the cord blood of fetuses to rule out other disorders have found high pyruvate kinase activities at 17-24 weeks' gestation that can be explained on the basis of a younger red cell population. ${ }^{3}$ Our results prove that prenatal diagnosis of pyruvate kinase deficiency by enzyme activity assays is feasible in those variants with a marked loss of activity and can probably be made as soon as 17 weeks' gestation.

Characterisation of pyruvate kinase cDNA in some patients with pyruvate kinase deficiency has been achieved recently. Dot blot hybridisation of polymerase chain reaction amplified genomic DNA from a homozygous pyruvate kinase deficient patient (PK Tokyo) showed a single nucleotide substitution (ACG to ATG) at nucleotide 1151 of the coding sequence of the $R$ type pyruvate kinase that caused a change of amino acid threonine to methionine. This same point mutation has been found in two other unrelated patients from different countries. Further studies in other unrelated patients indicate that the multiplicity of mutant pyruvate kinase alleles is smaller than expected. ${ }^{4} 5$ Although no prenatal molecular diagnosis for pyruvate kinase deficiency has been made, it is obvious that it will soon be available.

When there is a history of previous anaemic non-immune hydrops of unknown aetiology and no index case is available, parental studies must be carried out, especially if consanguinity is present. Heterozygous carriers of pyruvate kinase deficiency usually have values of pyruvate kinase activity around $50 \%$ the normal value and diminished activity of the enzyme in the parents suggests its deficiency as the cause of haemolysis in the child. Hydrops fetalis and early neonatal death have also been described in other rare red cell deficiencies of hexokinase, glucose phosphate isomerase and triose phosphate isomerase, as well as secondary to haemolytic crisis caused by maternal ingestion of oxidant agents in glucose-6-phosphate deficiency. ${ }^{167}$ When other more frequent causes of hydrops fetalis are ruled out red cell enzyme deficiencies and especially pyruvate kinase deficiency must be considered. Fetal ultrasonography and cord sampling may allow prompt diagnosis and if necessary intrauterine transfusion can be considered.

We thank Elena Salinas and Mr Juan Torres for their diligence and work.

1 Paglia DE. Enzymopathies. In: Hoffman R, Benz Jr EJ, Shattil SJ, Furie B, Cohen HJ, eds. Hematology. Basic prin ciples and practice. New York: Churchill Livingstone, 1991: 504-13.

2 Beutler E. Red cell metabolism. A manual of biochemical methods. New York: Grune and Stratton, 1975.

3 Lestas AN, Rodeck CH, White JM. Normal activities of glycolytic enzymes in the fetal erythrocytes. Br f Haematol glycolytic enzymes

4 Kanno H, Fujii H, Hirono A, Omine M, Miwa S. Identical point mutation of the R-type pyruvate kinase (PK) cDNA found in unrelated PK variants associated with hereditary hemolytic anemia. Blood 1992; 79: 1347-50

5 Neubauer B, Lakomek M, Winkler H, Parke M, Hofferber S, Schöter W. Point mutations in the L-type pyruvate kinase deficiency. Blood 1991; 77: 1871-5

6 Machin GA. Hydrops revisited: literature review of 1414 cases published in the 1980s. Am f Hum Gemet 1989. 34: 366-90.

Ravindranath Y, Paglia DE Warrier I, Valentine WN, Nakatani M, Brockway RA. Glucose phosphate isomerase deficiency as a cause of hydrops fetalis. NEngl f Med 1987; 316: 258-61. 